Article

\title{
Knowledge, Fear, and Conscience: Reasons to Stop Flying Because of Climate Change
}

\author{
Nina Wormbs ${ }^{1, *}$ and Maria Wolrath Söderberg ${ }^{2}$ \\ ${ }^{1}$ Division of History of Science, Technology and Environment, KTH Royal Institute of Technology, 10044 Stockholm, \\ Sweden; E-Mail: nina.wormbs@abe.kth.se \\ 2 Division of Rhetoric, Södertörn University, 14189 Huddinge, Sweden; E-Mail: maria.wolrath-soderberg@sh.se \\ * Corresponding author
}

Submitted: 28 December 2020 | Accepted: 18 March 2021 | Published: 9 June 2021

\begin{abstract}
Much research on the societal consequences of climate change has focused on inaction, seeking to explain why societies and individuals do not change according to experts' recommendations. In this qualitative study, we instead consider people who have changed their behaviour for the sake of the climate: They have stopped travelling by air. We first asked them to elaborate their rationales for the behaviour change. Then, using topos theory to find thought structures, we analysed their 673 open-text answers. Several themes emerged, which together can be regarded as a process of change. Increased knowledge, primarily narrated as a process by which latent knowledge was transformed into insight, through experience or emotional distress, was important. Contrary to certain claims in the literature, fear stimulated change of behaviour for many in this group. Climate change was framed as a moral issue, requiring acts of conscience. Children were invoked as educators and moral guides. Role models and a supportive social context played an important part. Alternatives to flying were brought forward as a motive to refrain from flying. Only a few mentioned shame as momentous. Instead, stopping travelling by air invoked a feeling of agency and responsibility, and could also result in a positive sensation.
\end{abstract}

\section{Keywords}

arguments; children; climate change; flight shame; inner deliberation; knowledge-action gap; stop flying; topos

\section{Issue}

This article is part of the issue "Cities, Long-Distance Travel, and Climate Impacts" edited by Jukka Heinonen (University of Iceland, Iceland) and Michał Czepkiewicz (University of Iceland, Iceland / Adam Mickiewicz University in Poznań, Poland).

(C) 2021 by the authors; licensee Cogitatio (Lisbon, Portugal). This article is licensed under a Creative Commons Attribution 4.0 International License (CC BY).

\section{Introduction}

Although the UN has declared this the Decade of Action, during which the UN Sustainable Development Goals (SDGs) should be met, progress toward SDG No. 13"Take urgent action to combat climate change"-has been slow. Much research has been dedicated to understanding this inertia (Hulme, 2009; Oreskes \& Conway, 2010). One prominent explanation for why people fail to act on the knowledge they possess has been characterised as the knowledge-action gap. This gap has spurred research in many fields, including media and communication studies (Kollmuss \& Agyeman, 2002;
Moser \& Dilling, 2011), anthropology (Norgaard, 2011), and psychology (Gifford, 2011). An alternate explanation characterises climate change as a "wicked problem" (Levin, Cashore, Bernstein, \& Auld, 2012), laden with goal conflicts. Goal conflicts are at play on several levels, from the micro to macro. For instance, some of the SDGs actually stand in conflict with each other when more precisely articulated (Nilsson, Griggs, \& Visbeck, 2016). On the level of individuals, the ambition to lead a climatefriendly life may stand in conflict with eating the food one loves or maintaining international friendships.

We are interested in how individuals and societies manage goal conflicts and overcome the inertia of 
inaction concerning climate change. Travelling by air was chosen as a distinctive case, as flying typically presents an individual with several, potentially painful goal conflicts. Considering Swedes who stopped or drastically reduced their amount of travel by air because of stated concerns about climate change, we analyse the thought structures that they report motivated their decisions. The analysis is qualitative and the results are not generalizable. Our interest is the particular and non-representative group that overcame inertia and changed behaviour. In the Swedish population as a whole, very few have made this decision. In a general survey of Swedes and their attitudes toward climate and environmental issues, $14 \%$ said they had stopped flying for climate reasons in 2019 (Persson, 2020). However, studying this particular group illuminates the arguments that these people brought forward as they curtailed flights, and this, in turn, can give important insights into the work of further limiting emissions from commercial air travel.

To date, very few studies look specifically at people who have eliminated air travel because of concern about climate change. Jacobson, Åkerman, Giusti, and Bhowmik (2020) conducted interviews with a total of 25 "quitters," "reducers," and "non-reducers" and found phases and components of a process of transformation. Jacobson et al. (2020) show that internalised knowledge about climate change and the impact of air travel is crucial for instigating behavioural change. To investigate the role of values, Büchs (2017) likewise made interviews with people who voluntarily reduced flying. In a recent study, Mkono and Hughes (2020) have analysed how people relate to flying on social media, gathering examples of online discourse. They found that eco-guilt and ecoshame are common; their study objects, however, in general, did not cease travelling by air. The literature on people who continue flying despite their otherwise sustainable values is larger (e.g., Cohen \& Higham, 2011; Juvan \& Dolnicar, 2014; Kroesen, 2013; McDonald, Oates, Thyne, Timmis, \& Carlile, 2015).

As a situated understanding of flying is important for individual motives, the next section relates to the Swedish context. The theoretical underpinning of our research design is discussed in Section 3, followed by a description of the methodology in Section 4. Section 5 details our empirical findings and Section 6 discusses the array of findings in relation to each other.

\section{Flying and Climate Change in Sweden: Some Context}

Air travel as an issue related to climate change is not new. The first Intergovernmental Panel on Climate Change (IPCC) report on the topic was published in 1999 (Penner, Lister, Griggs, Dokken, \& McFarland, 1999). As a public topic for people in general, however, it was probably not an issue until climate change gained wider attention in the media. This occurred markedly in 2007, with news around the publication of the IPCC Fourth Assessment
Report and Al Gore's film An Inconvenient Truth winning an Oscar, and even more so in 2009, with the hacked email from East Anglia and the COP15 meeting in Copenhagen (Boykoff, 2010).

In the Swedish context, early well-known examples of people who stopped flying include the climate researcher Kevin Anderson, and opera singer Malena Ernman, better known to international audiences as the mother of Greta Thunberg (Anderson, Andersson, Ferry, Ernman, \& Hedberg, 2017; Ernman \& Thunberg, 2018). By 2018, the Swedish public sphere saw an extensive discussion on flying habits and climate change. Occurring close in time but acting separately, three public figures published columns in the daily press detailing their personal struggles with flying. They testified to the goal-conflicts and troubled consciences they experienced when considering the large carbon dioxide emissions from trips they took to Kenya, Cuba, or Italy (Hadley Kamptz, 2018; Liljestrand, 2018; Mosskin, 2018). An intense and prolonged debate on flying in general and leisurely flying in particular followed, and to some extent continues in Sweden. The term 'flight shame' emerged, not as a precise scientific description of a psychological reaction, but as a loose and click-friendly response to an emotional discourse in which social media was key. In early 2019, an anonymous Instagram account began shaming so-called influencers who flew extensively and at the same time declared an interest in climate issues; to post pictures of long-distance trips on Facebook was no longer comme il faut. Most organised efforts to stimulate decreased flying were, however, supportive, such as the We Stay on the Ground movement. Their campaign on Facebook is also organised around positive examples and avoids shaming, even though it engages with moral issues. Still, 'flight shame,' translated from Swedish, began circulating internationally in debates (Eriksson, Pargman, Robèrt, \& Laaksolahti, 2020; Gössling, Humpe, \& Bausch, 2020). The phrase established a common understanding that this particular mobility discussion was tightly coupled with one of the most difficult human emotions: shame.

Furthermore, the record-breaking Summer of 2018 saw extreme temperatures and extensive forest fires in Sweden. In the Fall, as the new school term began, the then 15-year-old Greta Thunberg started her School Strike for Climate under the hashtag \#FridaysForFuture. It soon resulted in a social movement of global proportions (Wahlström, Kocyba, De Vydt, \& de Moor, 2019). Mainstream and social media coverage increased dramatically (Boulianne, Lalancette, \& Ilkiw, 2020; Mahl, Brüggeman, Guenther, \& De Silva-Schmidt, 2020). It was in this national context that our survey was carried out.

\section{Theoretical Basis and Methodological Starting Points}

Our main interest is to understand the circumstances that allow people to change their behaviour with regards to climate change. A starting point is the hypothesis 
that people orient and motivate action in dialogue with others, always against the background of a social context, but also through an internal dialogue where people negotiate with themselves. From a rhetorical perspective, this sort of human meaning-making is linguistic and argumentative. When we want to understand what enables action, or promotes inaction, we can look at how someone reasons or argues (this does not exclude the existence of other, non-linguistic dimensions). This rhetorical perspective is particularly relevant in issues where there is tension between knowledge and action, between different important values, or between short-term and long-term goals. In A Rhetoric of Motives, Burke (1969) argues that meaning-making in such matters takes place through identification and division. Burke (1969) proposes that people act based on how they identify and separate themselves from other people, ideas, thought systems, events, and things, and that these identifications also affect what people consider to be true and relevant. Burke (1984) uses the term motives to describe how people understand, explain, justify, excuse, or rationalize their actions to others and themselves, but also as "shorthand descriptions for certain typical patterns of discrepant and conflicting stimuli" (Burke, 1984, p. 30). Motives, according to Burke (1969), are not static. New knowledge, other social contexts, meetings, and dialogues can change how people perceive their moral situation and force or invite them into new patterns of meaning.

A prime assumption of rhetorical theory, already identified in Aristotle's Rhetoric, is that people want to be consistent and avoid contradictions. If people act against their intention or knowledge, or in a manner that contradicts their morals, they experience unease, which Festinger (1957) later called "cognitive dissonance." The occurrence of cognitive dissonance has been observed also in tourism studies, where for example Kroesen (2013) has used Q-methodology to study arguments used to overcome the discomfort of acting against knowledge. Likewise, Juvan and Dolnicar (2014) explore justifications concerning the discomfort of unsustainable tourism.

The drive to be consistent or coherent means that people strive to rationalize their behaviour. This rationalization, argumentation, or justification takes place in an inner dialogue, which Perelman and Olbrechts-Tyteca (1969) called "deliberation intime" in French. In our study, the action originally causing the cognitive dissonancetravelling by air despite knowing its negative effect on climate-was abandoned and thus few motives relate to justification. Instead, cognitive dissonance is revealed as a backdrop to behavioural change. This differs from most studies that engage with cognitive dissonance.

We focus on the thought structures that can be deduced from the arguments people use when explaining their motives, the structures by which they create and display coherence between knowledge and action. We are particularly interested in the prototypical thinking structure behind recurrent arguments used to explain a certain action. In rhetorical theory, this is called topoi (topos in singular). Topos theory, with its roots in ancient sophistry, was articulated by Aristotle in his Topica and Rhetorica. It was then explored and developed by several rhetoricians, including Cicero and Giambattista Vico. We start from the understanding of topos developed in the 20th century by Perelman and Olbrechts-Tyteca (1969), which gives an ideal conceptual frame for studying and describing rhetorical negotiation between multiple perspectives. The theory thus offers a methodology akin to, but still significantly different from, discourse analysis as exemplified by Foucault or frame analysis as practised by Goffman, since we look for specific traits within the material: namely, arguments that motivate the action and create meaning for the individual.

The theory of topos does not see reasoning as isolated from context. Even the internal dialogue takes place between topoi that have been developed and are perceived as valid in a social context. People use the arguments that have the potential to be accepted and make sense in the context they belong to or want to belong to. These social traits of reasoning have recently been observed also in psychology as motivated reasoning or cultural cognition, and challenge the enlightenment idea of rationality based on knowledge (Kahan, 2015; Mercier \& Sperber, 2017). In short, arguments are socially situated and also temporally and spatially dependent. Recurring types of argument can still be sorted into categories and described, albeit knowing that these categories and descriptions are contingent. We cannot expect to find universally valid or fully delimited topoi, or even a limited number of them.

To discern and describe this meaning-making we use phenomenography, a theory developed within pedagogy, with an empirical and interpretivist perspective (Marton, 1986; Marton \& Booth, 1997; Svensson, 1997). A basic assumption in phenomenography is that learning and meaning-making manifest themselves in many ways and that there is a value in discerning, describing, and understanding this variety. Phenomenography is also a methodology for qualitatively studying different ways of experiencing or thinking about something and describing a range or repertoire of possible approaches. This harmonizes well with topical analysis.

\section{Method}

This study applied a mixed qualitative method including several steps. We used a survey to collect free-text answers. The respondents were self-recruited from a special group, namely people who stopped flying because of concern about climate change. In the free-text answers, we distinguished recurring types of arguments motivating behavioural change. These types constitute different topoi. Each discernible topos received a tag in the digital survey tool used to analyse and sort the material. Tags that were similar to each other were sorted together in groups. These were in turn arranged in 
overarching categories that shared features. We expand on this method below.

The survey was open between May 29 and August 12, 2019, and was carried out via the tool Survey Monkey adhering to General Data Protection Regulation. It was published online on Twitter and in groups on Facebook that bring together climate-committed individuals as well as more specific groups such as Flight Free 2019/20 and We Stay on the Ground. Since we are interested in people who stopped flying due to concerns about climate change, we targeted groups with that profile. This approach can be compared to the sampling of Büchs (2017), who also looked for individuals within particular interest groups. It should be stressed that we did not seek to understand how people in general reason around climate change and air travel, nor in understanding the motives of those who stopped flying for economic, medical, or other reasons. This study focuses on those who actively changed flight behaviour due to concerns about climate change, and how they explain this change of behaviour. The answers were anonymous and in Swedish. We completed the translations into English.

The survey contained 15 questions, which included both open text and limited choice responses, and covered areas such as when did you fly or what kind of flying did you do. There were also questions related to age, gender, and education. A question central to this article was No. 6: "What made you change your behaviour?" This was a multi-choice question with the following options: a specific occasion, more knowledge or a new insight, specific arguments, role models or inspiring people, one or several people close to me, travelling alternatives, the debate, my social context or peer pressure, flight shame, bad conscience, I don't know, and other. Another central question was No. 7: "Tell us how it happened (open text)." The survey method allowed us to gather a large corpus of information in a relatively short time. A total of 673 individuals completed the survey and our analy sis builds primarily on the answers to question No 7. These 673 answers were of different length. Some were very short, a few words, and others longer, several hundred words. Regardless, they all contained at least one motive for changing behaviour. Most answers contained several motives. This means that our corpus comprised a great number of motives to stop flying because of concern about climate change. In traditional rhetorical critique, one generally analyses texts that have already been produced and have appeared in a particular context. Here we do something less common in rhetoric, but more common in phenomenography: namely, organizing the production of a material that we then study. The material is then analysed in the same way that rhetoricians examine artefacts.

We applied a phenomenological approach that seeks to capture a variation, a diversity of existing ways of thinking within a group. These ways of thinking are then described and organised from likeness in categories of description. The categories and their examples can then be related or compared with each other. Such a set of cat- egories capturing the variation of reasoning concerning a phenomenon is called an outcome space (Marton, 1986). We combined the phenomenographical method with topical analysis. In the material, we specifically searched for topoi, prototypical thinking structures behind arguments, or recurring traits in meaning-making. When sorting the topoi in categories of description we could discern motives such as certain types of knowledge, experience, emotions, and values, which are the focus of our discussion.

It is not possible for us as scholars to distinguish between actual experiences, knowledge, or emotions, and the way these are accounted for in the responses. What we have are the written articulations of phenomena. From a rhetorical perspective, thinking is to a high degree constituted linguistically, especially regarding problematic issues where one needs to deliberate between different choices. By studying the linguistic choices, we can discern key features in thinking. Some of the articulated motives in the survey may be postconstructions, but even those are illuminating as they reveal what is considered meaningful to the respondent.

It is also not possible to know if the motives given in the survey are the real motives of the respondents. This is true for most types of argumentative analysis and has to be taken into consideration. However, we believe that there are few reasons for the anonymous respondents to make up motives, in particular since this survey dealt with a change that the respondents wanted to make. A distinct advantage of our design is that we refrain from asking people about their intentions, which might very well be separate from the outcome, but instead ask them to account for something that has already happened. The multi-choice question preceding the open text question may have had an impact on the responses, which is a possible weakness in the survey.

Topos analysis can be done deductively, using for example a set of pre-defined topoi and identifying their occurrence. We instead worked inductively, considering each answer for the topoi. For example, an answer stating "For long, I have known that flying was bad for the climate, but when I visited Bangladesh and saw the flooding of the homes of poor people, I realised the severity of climate change and I cannot contribute to this unfairness anymore" displays several topoi. One is that latent knowledge can become a realization through eye-witnessing a climate change incident, another topos is the recognition of one's own contribution to the climate crisis, a third is to acknowledge a schism between personal behaviour and the severity of climate change, and a fourth is a justice perspective. None of these topoi are unique for reasoning concerning climate issues; in fact, they occur in reasoning around many issues, but they are prominent in this material.

Topos analysis has been used to analyse the rhetoric of climate change before (Cox, 1982; Farrell \& Goodnight, 1981; Myerson \& Rydin, 1996; Ross, 2013, 2017; Walsh, 2017; Walsh \& Boyle, 2017). Concrete examples are 
Kerr (2017), who studied how uncertainty was used by both environmental activists and companies in the fracking debate; Ceccarelli (2011), who studied how the same topos is used to give the appearance of scientific controversy and to postpone regulation; Walker and Walsh (2012), who looked at how environmental activists emphasize risks; and Walsh and Prelli (2017), who focused on how scientific models are understood and used in climate communication and by climate change deniers.

In our previous report on this study, we presented the topoi found in detail and gave an abundance of examples (Wolrath Söderberg \& Wormbs, 2019). Here, we instead focus on the motives discerned behind the topoi and give a more overarching analysis of the process of change.

\section{Results}

Our inductive method resulted in a great number of possible motives for change, including within single individuals; it was common to describe several rather than singular motives, and these furthermore often made up a process of change comprising several stages and motives. Below, we place these different types of motives, or topoi, in nine different thematic categories, even if there are great overlaps and connections between them, and end with the process of change. In the material, there are also several more infrequent motives that we leave aside in this analysis.

\subsection{Knowledge}

The by far most common motive to stop or drastically reduce flying was, in the wording of the respondents, new knowledge. Among the pre-selected reasons to stop, four out of five ticked the box 'knowledge' and in the open text answers more than half of the responses dealt with knowledge. Some testified that they had had knowledge of the effects of flying on climate change for a long time, but now had internalised it, which resulted in change: "I have known, but just on the outside. When I internalised it and it became part of me, there was no going back." This process is both described as successive and sudden. Knowledge accumulates over time, somewhat uncomfortably, and then something happens resulting in an insight. Some respondents realised the severity of climate change, which made knowledge take a new form or resulted in an "epiphany." Several understood the relative weight of flying in relation to other emission sources, for example as the proportion of their own total footprint or a national or global average: "I read that emissions from Swedes flying equal that of car traffic. It made me realize how serious the problem of flying is" represented a prototypical example, based on the comparison. Sometimes this understanding had come by way of using a climate calculator, which would calculate impact based on one's own data.

Common to many of these arguments and thought structures was the economic idea of an account or a bud- get. When learning about a global average, whether at present or representing an amount needed to meet the Paris Agreement over time, private flying stood out for many and was an obvious candidate in a quest to lower personal emissions.

\subsection{Experience}

Tightly connected to knowledge and with great overlap was the experience of climate change. The recordbreaking Summer of 2018 constituted a bodily experience of what many interpreted as climate change. The smoke from burning forests, the dried-out wells, and the continuous heat were all experiences that respondents brought up as momentous in a process of awareness, providing a compelling insight, allowing knowledge to become real: "The warm and dry Summer of 2018 [with] forest fires and sinking levels of groundwater made me fear the consequences of future climate change." There were, however, also examples that related to experiences, not in Sweden but elsewhere:

My last flight was in November 2017 to Bangladesh for work. [T] he ocean makes Bangladesh so exposed to rising sea levels. A few weeks earlier, colleagues had been in Dhaka, which was flooded, and they described how they drifted in taxis with water up to the windshield. Their luggage was in the trunk, all soaked. I met people there who will most likely be hit by climate change, much harder than I. Yet I am the one causing these emissions. I felt there and then that I did not have any right to fly.

\subsection{Emotions}

The experience referred to above could also be expressed in emotional language, like worry in the face of lack of drinking water, or fear of fire and drought. Often these emotions were part of the process of experience that made knowledge real. But emotions were also brought forward in other settings, not connected to an experience. People wrote about anxiety, fear, disgust, and sorrow, emerging after reading an article, watching a film, or having a conversation: "In 2018, I realised the seriousness of the damage from flying in earnest and it gave me climate angst and panic." Another kind of emotion had to do with mourning the loss of the journeys, or lifestyle, one must refrain from: "Surfing in exotic places and snowboarding in the Alps was part of my lifestyle." After having decided to quit flying, other emotions could emerge, like relief: "I still have a positive feeling from having made this decision."

\subsection{Moral}

Prevalent in the material were the responses that treated flying as an ethical issue, belonging to the sphere of personal morality. A great number of answers pointed to a 
"bad conscience" due to one specific trip or many historical trips. But it could also be due to the perceived injustice that climate change results in, and the realization of personal contributions to emissions. Some included people on other continents or future generations when assessing the ethics of flying. Feelings of guilt were often expressed also in physical terms, as bodily manifested stomach pain, the parable of an aching soul, or an inner conflict that needed to be solved: "I felt disgusted by the entire concept of flying and the unsustainable, egoistic impact it has on climate."

Others mentioned how they "stopped fooling" themselves, pointing to a moment of realization and consequence. This argument suggests the importance of consistency for rhetorical actors: You should "practice what you preach." Respondents could not justify their actions to themselves anymore and needed to stop. In fact, this version of the ethical argument was most common in the survey: "What you cannot defend, you should not do, and thus I stopped flying."

To be consistent, avoiding an internal crack or cognitive dissonance, is also part of striving to be a role model for others. Many related arguments talk about the possibility to change the norm and inspire others, which cannot be done if you are not walking the talk. The most important audiences in this regard were future generations, primarily children and grandchildren. The need to be able to "look them in the eye" captures the moral position.

There are also absolute and internal positions in no need of an external audience. Some talk about responsibility, the need to do one's "share" and contribute. Some simply say that flying is unjust, building on the understanding mentioned above that climate justice is key and that they have no "right" to fly. Others do not want to contribute more emissions, whether a specific temperature target is reached or not. The important thing is to act according to a moral conviction: "I simply could not find any more good excuses to ignore my values."

\subsection{Children and the Future}

As previously mentioned, children show up as an important audience that one must face and answer to: "I decided [to stop flying] since I borrow the Earth from my children and I want to be able to look my grandchildren in the eye." They also carry knowledge and challenge habits and norms: "Our daughter has taken the lead. Now the entire family eats vegetarian, we drive an electric car, and have stopped flying." Children might object to flying or contribute an argument concerning a family vacation choice. At the same time, they figure prominently as embodying the future: "I love travelling to Asia, but I love my children more and therefore I will stop flying until the fuel is fossil-free." Many responses mention their own children or children close to them as a turning point, putting things into perspective and enabling change: "When my daughter was born, I had no more excuses to fly." To become a parent or see a new life enter the world is brought forward as a motive to change behaviour.

\subsection{The Public Debate and Role Models}

Many respondents claim to have been influenced by the wider public debate. This debate took place in traditional media, but just as often social media, and particular groups are mentioned where news pieces might have circulated. Contexts such as a Facebook group or similar could offer social support. The debate itself could also serve not just as an information provider but also as an inspiration.

The most influential person and role model in the material is Greta Thunberg. "I listened to Greta. I read up. And I decided." Greta Thunberg seems to have been able to transform latent knowledge for some at the same time as she reached new audiences. Thunberg's mother, Malena Ernman, is also frequently mentioned in the material with the book she co-authored and her decision not to fly. Al Gore and An Inconvenient Truth, Naomi Klein and This Changes Everything, and David Attenborough's recent TV-series are furthermore brought forward as important sources of knowledge and inspiration.

\subsection{The Social Context}

Greta Thunberg, then a child, was only matched by other anonymous children or children in the family. As mentioned above, it was very common that children influenced the behaviour of our respondents: "My teenage daughter said no to weekend trips" captures part of a process of change. Also, other issues are mentioned, such as a change in diet or a more sustainable lifestyle in general. Other people close to respondents can also be important, like a spouse, a sibling, or a friend. In those interactions, how a question was posed is often mentioned; empathy and courage are successful ingredients in such a process.

Family can be of great help in behavioural change: "When the debate became more intense and my husband gained more knowledge on the climate issue, we decided together to stop flying." Friends or colleagues can have influence and lead the way. But a large number of respondents referred to groups on social media as decisive for their decisions: "It is not possible to fly when you know how much $\mathrm{CO}_{2}$ it emits, to then see the flight free campaign also makes the decision more lasting as you know we are just becoming more and more." It is important to remember that the survey was conducted in precisely such groups.

\subsection{Shame}

Finally, shame is mentioned in the material, but only a few times. Conscience, and other notions having to do with morality, is much more common, as discussed 
above. Shame is thus not very visible, neither in the open-text answers nor among the pre-selected alternatives. Like with every word in the responses, we have taken them at face value but at the same time looked at their context and the argumentative structure. Shame is often understood as a socially formed conscience. Respondents mention many examples of social or media discourses that apparently impacted their decision to stop flying, either as role models or through normative or moral discussions. There is a social dimension of conscience, not mentioned as a negative feeling by the respondents, but rather as a kind of support to be the person one wants to be.

\subsection{Alternatives}

A large and distinct theme in the responses regards motives related to the existence of alternatives to longdistance flying. This theme could reveal a push from flying (e.g., "to fly is transport, not experience"), or a pull towards train travel, as in "I had forgotten how fun it is to travel by train." The possibility to travel by train is also filled with new meaning and slow travel is regarded as more attractive: "Trains are nicer. I prefer the tempo and think it is both more adventurous and pleasant." The time dimension can also be on a different scale: "You do not gain time through flying, but lose a future for coming generations," illustrating that the trope of saving time might not apply. Furthermore, one does not have to travel far to experience something different, as there are many parts of Sweden to visit: "Vacation in Sweden instead. Simpler, cheaper, nicer!”

\subsection{Process of Change}

The motives analysed here can be brought together in a process-catalogue of how change might happen. Not everyone in our study experiences everything, but the experiences seem to occur in about the same order and similar relations in the material. There are also several responses where the stories are detailed. Below is one example which illustrates the process, invoking several of the motives that were previously mentioned:

I have long regarded myself as climate-friendly and done loads of things to lower my emissions. Then I saw the figures on how much a flight emits and realised that a flight to New York corresponds to all my emission during an entire year if I live like I want to this year. It feels like everything else I do for the climate is of no use if I continue flying. Greta made me raise my ambitions because she made me dead scared for my future. And I am grateful for that. Even if I might not have a reasonable future since most people don't understand the gravity of the situation, I can still say to the next generation that I did all I could, before it was too late.

\section{Discussion}

By reducing or stopping flying, our respondents have overcome the cognitive dissonance common for those who strive to live a sustainable life but continue flying. What we see in their given motives for change, however, are often residues of that dissonance and a story of transformation where several motives support each other and interact. For example, strong emotions seem to allow for new knowledge and a social context can help behavioural change. Below we unpack the nine different thematic categories and the process of change brought forward above.

In this study, knowledge surfaces as the single most important factor of any referred to by our respondents. This is consistent with findings in Jacobson et al. (2020). Important knowledge is particularly that which mediates the acuteness of the climate crisis and the size and proportions of emissions that allow for comparison. Also, and just as interesting, are the processes by which knowledge is experienced and hits close to home. When that happens, the earlier accumulated knowledge becomes real and meaningful and internalised. This is an interesting finding. There is a questioning of the power of knowledge in the very description of the inertia in climate change as a gap between knowledge and action. But there are also studies that more explicitly criticize the possibility to bring about behavioural changes by informing people about climate change, the so-called information-deficit model (Bulkeley, 2000; Moser \& Dilling, 2011; Norgaard, 2011). These studies, which strive to explain why people do not change, have not completely rejected knowledge but rather emphasised that knowledge alone is not enough. In this context, the concept of knowledge is that of scientific discrete factual knowledge. The knowledge concept that our respondents bring forward is more complex and integrated with experiential, emotional, moral, and social dimensions.

By and large, the aggregated process is often connected to strong emotions, like fear, worry, and pain. Increased responsibility to others far away, both geographically and temporally, are also emotionally challenging. Before, during, and after the decision to stop or reduce flying, feelings of loss and grief are mentioned. The loss could be related to not being able to meet friends and family or to abstain from activities that were dear, if not existential. The decisions that people have made are not easy, which is also apparent in the responses to a specific question in the survey on hindrances to change. In general, it should come as no surprise that change is hard and painful. As Moser (2019, p. 152) recently put it, "deep change is-first and foremost-experienced and processed emotionally" (see also Randall, 2009, for a similar discussion on the importance of emotional engagement).

The respondents in our survey seem to experience strong agency through the action of stopping flying. They refute the idea that their flight is a drop in the ocean 
and thus can be overlooked; they do not want to contribute even a single drop. For them, individual emissions are real and the quickest way to lower them is to stop flying. It seems to be empowering. This is truly interesting, particularly regarding the hypothesis that non-action can be partly explained by the fact that people are scared into passivity and powerlessness (Stoknes, 2015). Several studies have analysed the effect of appeals to fear (or rather alarmist discourse) and concluded that it does not work (Jost et al., 2007; Moser, 2007; O'Neill \& Nicholson-Cole, 2009). This insight has been connected to studies that have shown that hopeful messages can promote action (Bennett et al., 2016; Stern, 2012), which in turn often led to the simplified conclusion in the climate communication discourse that one should communicate hope rather than fear (Shanahan, 2007; Stoknes, 2015). Our findings show that fear can be a driving force for behaviour change, which is supported also by Kleres and Wettergren (2017). This applies to fear as an emotion grounded in realizing the severity of climate change, which is not the same as saying that alarmist messages work.

Personal morality, often expressed in terms of conscience, is a category of particular interest and with different forms. This is consistent with the findings of Büchs (2017). One form of morality is justice, which can surface when individual emissions are made visible and material, and when associated with the Paris Agreement or a global average. This dimension seems to make knowledge ethical. Knowledge of what is sometimes called inequality invokes moral action. The term 'responsibility' is recurrent, which puts the individual in relation to others, either other people far away or future generations. Frequently this is connected to the maintenance of the self as a consistent whole. However, it also expands to the category of children and future generations.

The public debate and the social context are invoked among the motives for change in our material. The change process seems to be facilitated by a social context in which experience can be shared (e.g., groups on the internet, at work, or at home), or by inspiring role models and good examples. This is well known in the health sector. However, identifying alternative ways to live or be is also important. In fact, the process by which knowledge becomes real may be facilitated by a supporting social context. This would be in line with the theory of cultural cognition where human rationality is believed to be deeply social (Mercier \& Sperber, 2017), and supported by research on deliberative social change processes and learning (Wals \& Rodela, 2014). Our respondents display a deliberative individual rationality, a rationality that is emotionally grounded, morally responsible, and socially dependent.

Shame, which has taken centre stage in the Swedish context and, so to speak, acquired wings of its own, is not frequent nor articulated in the material. This is contrary to the common understanding of what feelings might be associated with stopping to fly (Mkono \& Hughes, 2020).
Instead of invoking shame, our respondents talk about conscience or sometimes guilt. As this is of interest in the larger discussion on behavioural change, these findings need unpacking.

Shame is arguably a feeling that comes from a mismatch between how the outside world views you and how you view yourself. Shame can also be understood as a tension between who you identify as and how you act. Guilt, on the other hand, can be felt without an audience and be entirely an internal experience. Guilt appears when people do things they consider morally problematic, but without experiencing it as a threat to their perceived identity (Bedford \& Hwang, 2003).

Shame, understood as a social emotion, is rather absent in the material. However, it is clear that the moral understanding of and reasoning about flying has been impacted by a changed public and social discourse. The social discourse of our respondents is described as supportive rather than shaming. It is also probable that our respondents, who have stopped flying, are less likely to relate to shame. Shame as an issue of identity resonates with looking at the internal deliberation as a conversation between the person you want to be and the choices that you make. From this viewpoint, the dissonance is not only cognitive but might also threaten one's perceived identity. This is for instance visible in the wish to look "future children in the eye." The two ways of understanding shame come together as two dimensions of the same emotion; the topoi include internalization of the gaze and expectation of an 'other.'

Guilt, felt when failing to meet one's moral standard, is abundant in the answers that bring up moral dimensions. Although a social context is discernible, it is not necessarily integrated or highlighted as a motive stated by the respondent. Respondents instead often view themselves as autonomous and bring forward motives stressing responsibility or justice.

Even though guilt and shame can be intellectually and emotionally separated, it might be more useful to view them as two perspectives on the same phenomenon. This would correspond to a rhetorical understanding of meaning-making as simultaneously social and identity-building. Furthermore, in the Swedish context, the words shame and guilt often come together ('skam' and 'skuld') and there are reasons to believe that the distinction is not witheld in the public discourse. There are also reasons to conflate them according to a media logic that privileges strong negative feelings over empathetic reasoning. To feel shame is indeed most disturbing and deeply negative, and thus talking about flying and shame is a functional way of colouring the entire discourse. To many of our respondents, the moral dimension is crucial, but the social discourse is supportive rather than shaming.

To our knowledge, there are thus far no attribution studies that can assert that those who stopped flying are the ones primarily using the term flygskam, nor engage in flight shaming, as some scholars have suggested (Mkono, 
2020). On the contrary, the We Stay on the Ground movement explicitly works to avoid shame (Rosén, 2019). We believe it is more likely to be used by flyers to characterize and thereby dismiss a potentially disruptive movement, but more research is needed.

The last thematic category in our list, alternatives, can also be seen as part of a process of change, just like the social context. In theory, these alternatives exist to all, and the literature on sustainable tourism illustrates the complexity of the larger issue (Becken, 2019; Pyke, Hartwell, Blake, \& Hemingway, 2016), but the alternatives become real only when it is possible to assess them as alternatives. Then they support the original issue of stopping flying. We suggest that it is not only the will to change behaviour that affects the willingness to find alternatives, but that the awareness of attractive alternatives also affects the ability to take on new knowledge.

Finally, as for the process of change, this is analogous to Vladimir Propp's structural elements of a story. He mapped 31 basic functions of a fairy tale. Not everyone is included in every story, but those who are often appear in a specific order and relationship to each other: The hero leaves the home. The hero is warned against some action. The hero does not listen to the command. The villain enters the story. The villain seeks information and later deceives the victim, etc. (Propp, 1968). We can discern a story of change in our material of separate arguments. This relates well to the study by Jacobson et al. (2020), where they describe a "tipping point" when awareness evokes negative emotions leading to a decision to reduce or quit flying and discern the workings of conscience and social discourse.

\section{Conclusion}

Contrary to existing understanding, knowledge and fear are brought forward as important factors for change among those who stopped or drastically reduced flying for climate reasons in this study. This underscores the importance of further studying which knowledge enables action, and if and how it can be promoted. The inner emotional conflicts that climate change brings about are also important. Moreover, the role of social context is underscored. Children, in particular, serve as those who bring knowledge, awaken conscience, demand consistency, and embody the future. It is particularly interesting to see how these dimensions-knowledge, emotions, and social context-speak to conscience, and interact with a sense of individual responsibility.

Finally, the sense of moral agency among our respondents is noteworthy. Not only is it contrary to a widespread assumption on maximizing personal gain, but it is also rewarding to watch a transition process take form.

\section{Acknowledgments}

The research for this article was carried out within the project "Understanding the Justification of Cli- mate Change Non-Action," funded by Riksbankens Jubileumsfond (P18-0402:1).

\section{Conflict of Interests}

The authors declare no conflict of interests.

\section{References}

Anderson, K., Andersson, H., Ferry, B., Ernman, M., \& Hedberg, M. (2017, June 2). I den akuta klimatkrisen väljer vi nu bort flyget [During the imminent climate crisis, we decline flying]. Dagens Nyheter. Retrieved from https://www.dn.se/debatt/ i-den-akuta-klimatkrisen-valjer-vi-nu-bort-flyget

Becken, S. (2019). Decarbonising tourism: Mission impossible? Tourism Recreation Research, 44(4), 419-433.

Bedford, O., \& Hwang, K.-K. (2003). Guilt and shame in Chinese culture: A cross-cultural framework from the perspective of morality and identity. Journal for the Theory of Social Behaviour, 33(2), 127-144.

Bennett, E. M., Solan, M., Biggs, R., McPhearson, T., Norström, A. V., Olsson, P., . . X Xu, J. (2016). Bright spots: Seeds of a good Anthropocene. Frontiers in Ecology and the Environment, 14(8), 441-448.

Boulianne, S., Lalancette, M., \& Ilkiw, D. (2020). "School Strike 4 Climate": Social media and the international youth protest on climate change. Media and Communication, 8(2), 208-218.

Boykoff, M. (2010). Indian media representations of climate change in a threatened journalistic ecosystem. Climatic Change, 99(1), 17-25.

Büchs, M. (2017). The role of values for voluntary reductions of holiday air travel. Journal of Sustainable Tourism, 25(2), 234-250.

Bulkeley, H. (2000). Common knowledge? Public understanding of climate change in Newcastle, Australia. Public Understanding of Science, 9(3), 313-333.

Burke, K. (1969). A rhetoric of motives. Berkeley, CA: University of California Press.

Burke, K. (1984). Permanence and change: An anatomy of purpose (3rd ed.). Berkeley, CA: University of California Press.

Ceccarelli, L. (2011). Manufactured scientific controversy: Science, rhetoric, and public debate. Rhetoric \& Public Affairs, 14(2), 195-228.

Cohen, S. A., \& Higham, J. E. S. (2011). Eyes wide shut? UK consumer perceptions on aviation climate impacts and travel decisions to New Zealand. Current Issues in Tourism, 14(4), 323-335.

Cox, J. R. (1982). The die is cast: Topical and ontological dimensions of the locus of the irreparable. Quarterly Journal of Speech, 68(3), 227-239.

Eriksson, E., Pargman, D., Robèrt, M., \& Laaksolahti, J. (2020). On the necessity of flying and of not flying: Exploring how computer scientists reason about academic travel. In A. Moreira (Ed.), ICT4S2020: Proceedings of the 7th International Conference on ICT for 
Sustainability (pp. 18-26). New York, NY: Association for Computing Machinery.

Ernman, M., \& Thunberg, S. (2018). Scener ur hjärtat [Scenes from the heart]. Stockholm: Polaris.

Farrell, T. B., \& Goodnight, G. T. (1981). Accidental rhetoric: The root metaphors of Three Mile Island. Communication Monographs, 48(4), 271-300.

Festinger, L. (1957). A theory of cognitive dissonance. Stanford, CA: Stanford University Press.

Gifford, R. (2011). The dragons of inaction: Psychological barriers that limit climate change mitigation and adaptation. American Psychologist, 66(4), 290-302.

Gössling, S., Humpe, A., \& Bausch, T. (2020). Does 'flight shame' affect social norms? Changing perspectives on the desirability of air travel in Germany. Journal of Cleaner Production, 266, 122015.

Hadley Kamptz, I. (2018, January 16). Jag ser deras flygresor och min avund vet inga gränser [I see their travel and my envy is without limits]. Expressen. Retrieved from https://www.expressen.se/kultur/ isobel-hadley-kamptz/jag-ser-deras-resor-och-minavund-vet-inga-granser

Hulme, M. (2009). Why we disagree about climate change: Understanding controversy, inaction and opportunity. Cambridge: Cambridge University Press.

Jacobson, L., Åkerman, J., Giusti, M., \& Bhowmik, A. K. (2020). Tipping to staying on the ground: Internalized knowledge of climate change crucial for transformed air travel behavior. Sustainability, 12(5), 1994.

Jost, J. T., Napier, J. L., Thorisdottir, H., Gosling, S. D., Palfai, T. P., \& Ostafin, B. (2007). Are needs to manage uncertainty and threat associated with political conservatism or ideological extremity? Personality and Social Psychology Bulletin, 33(7), 989-1007.

Juvan, E., \& Dolnicar, S. (2014). The attitude-behaviour gap in sustainable tourism. Annals of Tourism Research, 48, 76-95.

Kahan, D. M. (2015). The politically motivated reasoning paradigm, Part 1: What politically motivated reasoning is and how to measure it. In R. A. Scott \& S. M. Kosslyn (Eds.), Emerging trends in the social and behavioral sciences (pp. 1-16). Hoboken, NJ: John Wiley \& Sons.

Kerr, J. (2017). Designing doubt: The tactical use of uncertainty in hydraulic fracturing debates. In D. G. Ross (Ed.), Topic-driven environmental rhetoric (pp. 187-210). New York, NY: Routledge.

Kleres, J., \& Wettergren, Å. (2017). Fear, hope, anger, and guilt in climate activism. Social Movement Studies, 16(5), 507-519.

Kollmuss, A., \& Agyeman, J. (2002). Mind the gap: Why do people act environmentally and what are the barriers to pro-environmental behavior? Environmental Education Research, 8(3), 239-260.

Kroesen, M. (2013). Exploring people's viewpoints on air travel and climate change: Understanding inconsistencies. Journal of Sustainable Tourism, 21(2), 271-290.
Levin, K., Cashore, B., Bernstein, S., \& Auld, G. (2012). Overcoming the tragedy of super wicked problems: Constraining our future selves to ameliorate global climate change. Policy Sciences, 45(2), 123-152.

Liljestrand, J. (2018, January 13). Jag är trött på att visa mitt barn en döende värld [I am tired of showing my child a dying world]. Expressen. Retrieved from https://www.expressen.se/kultur/jens-liljestrand/ jag-ar-trott-pa-att-visa-mitt-barn-en-doende-varld

Mahl, D., Brüggeman, M., Guenther, L., \& De SilvaSchmidt, F. (2020). Public opinion at a tipping point: Germany's path to engaging with climate change (Down to Earth Working Paper). Hamburg: University of Hamburg. https://doi.org/10.25592/uhhfdm.905

Marton, F. (1986). Phenomenography: A research approach to investigating different understandings of reality. Journal of Thought, 21(3), 28-49.

Marton, F., \& Booth, S. (1997). Learning and awareness. Mahwah, NJ: Erlbaum.

McDonald, S., Oates, C. J., Thyne, M., Timmis, A. J., \& Carlile, C. (2015). Flying in the face of environmental concern: Why green consumers continue to fly. Journal of Marketing Management, 31(13/14), 1503-1528.

Mercier, H., \& Sperber, D. (2017). The enigma of reason. Cambridge, MA: Harvard University Press.

Mkono, M. (2020). Eco-anxiety and the flight shaming movement: Implications for tourism. Journal of Tourism Futures, 6(3), 223-226.

Mkono, M., \& Hughes, K. (2020). Eco-guilt and ecoshame in tourism consumption contexts: Understanding the triggers and responses. Journal of Sustainable Tourism, 28(8), 1223-1244.

Moser, S. C. (2007). More bad news: The risk of neglecting emotional responses to climate change information. In S. Moser \& L Dilling (Eds.), Creating a climate for change: Communicating climate change and facilitating social change (pp. 64-80). Cambridge: Cambridge University Press.

Moser, S. C. (2019). Not for the faint of heart: Tasks of climate change communication in the context of societal transformation. In G. Feola, H. Geoghegan, \& A. Arnall (Eds.), Climate and culture: Multidisciplinary perspectives on a warming world (pp. 141-167). Cambridge: Cambridge University Press

Moser, S. C., \& Dilling, L. (2011). Communicating climate change: Closing the science-action gap. In J. S. Dryzek, R. B. Norgaard, \& D. Schlosberg (Eds.), The Oxford handbook of climate change and society (pp. 161-174). Oxford: Oxford University Press.

Mosskin, J. (2018, January 20). Flygets olidliga lätthet [The unbearable lightness of flying]. Dagens Nyheter. Retrieved from https://www.dn.se/kulturnoje/jonas-mosskin-flygets-olidliga-latthet

Myerson, G., \& Rydin, Y. (1996). The language of environment: A new rhetoric. London: UCL Press.

Nilsson, M., Griggs, D., \& Visbeck M. (2016). Policy: Map the interactions between sustainable development 
goals. Nature News, 534(7607), 320.

Norgaard, K. M. (2011). Living in denial: Climate change, emotions, and everyday life. Cambridge, MA: MIT Press.

O'Neill, S., \& Nicholson-Cole, S. (2009). "Fear won't do it": Promoting positive engagement with climate change through visual and iconic representations. Science Communication, 30(3), 355-379.

Oreskes, N., \& Conway, E. M. (2010). Merchants of doubt: How a handful of scientists obscured the truth on issues from tobacco smoke to global warming. New York, NY: Bloomsbury Press.

Penner, J. E., Lister, D. H., Griggs, D. J., Dokken, D. J., \& McFarland, M. (1999). Aviation and the global atmosphere. Geneva: IPCC. Retrieved from https://www.ipcc.ch/report/aviation-and-theglobal-atmosphere-2

Perelman, C., \& Olbrechts-Tyteca, L. (1969). The new rhetoric: A treatise on argumentation. Notre Dame, IN: University of Notre Dame Press.

Persson, S. (2020). Den svenska miljö-och klimatopinionen 2019 [Swedish opinions on environment and climate]. Gothenburg: Gothenburg University. Retrieved from https://www.gu.se/sites/default/ files/2021-03/Persson\%20-\%20Den\%20svenska \%20miljo\%CC\%88-\%20och\%20klimatopinionen \%202019.pdf

Propp, V. J. (1968). Morphology of the folktale (2nd ed.). Austin, TX: University of Texas Press.

Pyke, S., Hartwell, H., Blake, A., \& Hemingway, A. (2016). Exploring well-being as a tourism product resource. Tourism Management, 55, 94-105.

Randall, R. (2009). Loss and climate change: The cost of parallel narratives. Ecopsychology, 1(3), 118-129.

Rosén, M. (2019). Flygpratarguiden: Argument och strategier för klimatsamtal [We need to talk about aviation: A guide to having climate conversations]. Flygpratarguiden. Retrieved from http://www. flygpratarguiden.se

Ross, D. G. (2013). Common topics and commonplaces of environmental rhetoric. Written Communication, 30(1), 91-131.
Ross, D. G. (2017). Topic-driven environmental rhetoric. New York, NY: Routledge.

Shanahan, M. (2007). Talking about a revolution: Climate change and the media. London: International Institute for Environment and Development.

Stern, P. C. (2012). Fear and hope in climate messages. Nature Climate Change, 2(8), 572-573.

Stoknes, P. E. (2015). What we think about when we try not to think about global warming: Toward a new psychology of climate action. White River Junction, VT: Chelsea Green Publishing.

Svensson, L. (1997). Theoretical foundations of phenomenography. Higher Education Research \& Development, 16(2), 159-171.

Wahlström, M., Kocyba, P., De Vydt, M., \& de Moor, J. (2019). Protest for a future: Composition, mobilization and motives of the participants in Fridays For Future climate protests on 15 March, 2019 in 13 European cities. Keele: Keele University. Retrieved from https://eprints.keele.ac.uk/6571

Walker, K., \& Walsh, L. (2012). “No one yet knows what the ultimate consequences may be": How Rachel Carson transformed scientific uncertainty into a site for public participation in Silent Spring. Journal of Business and Technical Communication, 26(1), 3-34.

Wals, A. E. J., \& Rodela, R. (2014). Social learning towards sustainability: Problematic, perspectives and promise. NJAS-Wageningen Journal of Life Sciences, 69, 1-3.

Walsh, L. (2017). Understanding the rhetoric of climate science debates. Wiley Interdisciplinary Reviews: Climate Change, 8(3), e452.

Walsh, L., \& Boyle, C. (2017). Topologies as techniques for a post-critical rhetoric. Cham: Palgrave Macmillan.

Walsh, L., \& Prelli, L. J. (2017). Getting down in the weeds to get a God's-eye view: The synoptic topology of early American ecology. In L. Walsh \& C. Boyle (Eds.), Topologies as techniques for a post-critical rhetoric (pp. 197-218). Cham: Palgrave Macmillan.

Wolrath Söderberg, M., \& Wormbs, N. (2019). Grounded: Beyond flygskam. Stockholm and Brussels: Fores and ELF.

\section{About the Authors}

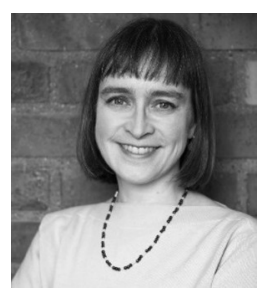

Nina Wormbs is a Professor of History of Technology at KTH Royal Institute of Technology. She has published on media history, technology-dependent commons, and Arctic issues, e.g., the edited volume Competing Arctic Futures (Palgrave, 2018). Recently, she has studied the normativity of scientific assessments and the temporal dimensions of climate change models.

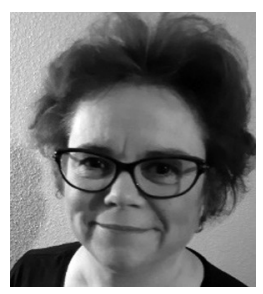

Maria Wolrath Söderberg is an Associate Professor in Rhetoric and Director of Higher Education Development, Södertörn University. Her interest is in the intersection of rhetoric and meaning-making in multifaceted issues. She has focused on how we negotiate knowledge, how we think with discursive tools, and how teaching can be designed to best promote learning. She has published on Aristotle, on topos theory, and on issues that contain a multitude of perspectives. Recently, she has focused on climate reasoning. 